\title{
Investigation of Effect of Age, Gender and Limb Dominance on Ankle Evertor/Invertor Peak Torque Ratios of Healthy Volunteers
}

\author{
Murat Ersoz, MD ${ }^{1)}$, Nilgun Simsir Atalay, MD²), FATMA KumBara, MD ${ }^{3)}$ \\ MUFIT AKYUZ, MD ${ }^{1)}$ \\ 1)Department of Physical Medicine and Rehabilitation, Ankara Physical Medicine and \\ Rehabilitation Training and Research Hospital of Ministry of Health \\ 2) Department of Physical Medicine and Rehabilitation, Pamukkale University Medical School: \\ 20210, Kinikli / Denizli, Turkey. TEL: +90 505-773-93-00, FAX: +90 258-211-81-29 \\ 3) Bahar Physical Medicine\& Rehabilitation Center
}

\begin{abstract}
Purpose] To determine the ankle evertor/invertor maximal torque ratios (E/I) in the normal population which could be used as reference values during clinical evaluations and rehabilitation efforts and also to investigate the effect of age, gender and limb dominance on E/I. [Methods] Concentric ankle E/ I was tested at 30 and 120 degrees/second using an isokinetic dynamometer for 79 healthy volunteers and the effects of age, gender, limb dominance on E/I were analysed. [Results] E/I values increased slightly with increasing age and there were statistically significant differences between age groups of 20-29 and 60-upper ages, and 30-39 and 60-upper ages with respect to left E/I (120 degrees/second) values. There were no significant differences between male and female subjects and between dominant and non-dominant limbs. [Conclusion] Ankle evertor/invertor peak torque ratios are affected by age but not by the dominance of the limb and the patient's gender. The ratios observed in different age groups in our study can be used as reference values in clinical evaluations and rehabilitation programs without taking into account the dominance of the limb and the patient's gender.
\end{abstract}

Key words: Ankle, Isokinetic, Peak torque ratio

(This article was submitted Mar. 30, 2009, and was accepted Apr. 17, 2009)

\section{INTRODUCTION}

Ankle injuries, specifically lateral ligament sprains, are a common sport-related problem ${ }^{1,2)}$. The high incidence of ankle sprain in athletes is a source of time and energy loss spent on treatment and rehabilitation ${ }^{3)}$. Ankle sprains are also a frequently faced problem for the normal population. After an ankle injury, residual symptoms can also affect activities of daily life. In a previous study, it was reported that $33 \%$ of patients with a lateral ankle sprain had persistent residual symptoms even two years after the initial injury ${ }^{4}$. Many factors are thought to cause ankle ligament injuries such as ligamentous instability, ankle muscle weakness, foot-ankle alignment abnormalities and generalized joint laxity ${ }^{5,6}$.

Freeman first described the term "functional ankle instability" (FAI) indicating a subjective feeling of "giving way" after repeated episodes of ankle sprain ${ }^{3)}$. Previous research on FAI has focused on a combination of factors, including muscle strength, mechanical instability and proprioception $^{7-9)}$. Basein and colleagues were the first to report that peroneal muscle weakness was the most significant factor contributing to recurrent 
ankle sprains ${ }^{3)}$. Peroneal muscle weakness has been theorized to cause diminished dynamic stability and therefore contribute to $\mathrm{FAI}^{10)}$.

Co-activation of antagonistic muscle groups has been identified as an important factor influencing dynamic joint stability ${ }^{11)}$. Traditionally, the strength ratios between these muscle groups have received considerable attention from clinicians during examinations and in monitoring rehabilitation progress. The advent of active isokinetic dynamometers allows the examination of the coactivation of agonist and antagonist muscle groups at a specific joint ${ }^{3}$.

Evertor/invertor strength imbalance is an important risk factor in ankle sprains ${ }^{1,12)}$. Strengthening of the evertor and invertor muscles is widely advocated as a key component of lateral ankle sprain rehabilitation ${ }^{12)}$. The normal evertor/ invertor ratio appears as a very important parameter in evaluation and reconstruction of the evertor/ invertor strength balance. Although investigation of peak torque values is also important, the ratio between agonist and antagonist muscles seems a more important parameter which would easily demonstrate the imbalance and the weak component, and enable strengthening of the weak muscle specifically.

In this study we investigated the effect of subject age, gender and limb dominance on E/I, because higher peak torque values in male subjects than female subjects, higher peak torque values in younger subjects than older subjects, and higher or lower peak torque values according to the direction of movement in the dominant and non-dominant limbs have been reported ${ }^{13-16)}$. We thought that if these factors do not have any effect on E/I, we could use a single $E / I$ ratio derived from normal subjects in daily practice. In a review of the literature, we could not find any study that had investigated the effect of age, gender and limb dominance on ankle $\mathrm{E} / \mathrm{I}$ ratio.

Briefly, the purpose of our study was to determine evertor/invertor maximal torque ratios $(\mathrm{E} / \mathrm{I})$ of healthy men and women which could be used as reference values during rehabilitation efforts and also to investigate the effect of subject age and gender and limb dominance on E/I.

\section{SUBJECTS AND METHODS}

\section{Subjects}

Seventy-nine right-handed healthy volunteers (32 men, 47 women; mean age $=38.2 \pm 13.8$ years) without prior history of ankle injury were enrolled in this study. An injury was defined as any sprain, strain or fracture of the ankle.

\section{Methods}

Ankle eversion, inversion strength ratios in both limbs were determined by using a computerized isokinetic dynamometer(Biodex Corp., Shirley, New York) for all participants. Subjects were positioned according to the manual of the system. The ankle joint was positioned in neutral, and inversion and eversion were identified using palpation during passive movements of the talus ${ }^{17}$. The knee of the test leg was positioned at $30^{\circ}$ flexion and the lower leg was parallel to the floor. The ankle joint was positioned at $10-15^{\circ}$ plantar flexion as a consequence of the low-cut lace-up shoe worn by each subject to simulate a position of inversion injury ${ }^{18)}$. Two straps criss-crossing the dorsum of the foot held it against the foot plate. The thigh stabiliser pad and strap secured the distal aspect of the thigh on the test leg and right and left seatbelts secured the torso.

Inversion and eversion range of motion were set within the subject's available range. Concentric eversion/inversion testing was performed at angular velocities of 30 and 120 degrees/second. Subjects had at least three experimental trials to familiarize themselves with the process at each angular velocity and performed 5 maximal repetitions at 30 degrees/ second and 10 maximal repetitions at 120 degrees/ second. Verbal encouragement for maximal effort was given to each subject throughout the testing procedure. None of the subjects felt any discomfort during testing. Concentric evertor/invertor peak torque ratios were automatically calculated by the data processing unit of the system by the formula (evertor peak torque / invertor peak torque x 100).

\section{Statistical Analysis}

The SPSS software Version 9.0(Chicago USA) was used for data analysis and $p<0.05$ was considered statistically significant. Descriptive statistics were performed. Concentric evertor/ invertor peak torque ratios at 30 and 120 degrees/ second were compared in five consecutive age 
groups $(20-29,30-39,40-49,50-59,60-$ older $)$ by one-way ANOVA and Tukey's HSD test was used for post hoc analysis. Significant differences between the dominant and non-dominant sides were investigated by the paired samples t-test. The effect of gender (male-female) was tested by the t-test for independent samples.

\section{RESULTS}

Subjects' mean age was $38.2 \pm 13.8$ years, mean height was $164.2 \pm 9.0 \mathrm{~cm}$, and mean body weight was $67.8 \pm 13.1 \mathrm{~kg}$.

Mean right E/I was $118.0 \pm 25.4$ and left $\mathrm{E} / \mathrm{I}$ was $115.7 \pm 27.3$ at 30 degrees/second, while mean right $\mathrm{E} / \mathrm{I}$ was $107.4 \pm 21.2$ and left $\mathrm{E} / \mathrm{I}$ was $107.6 \pm 25.0$ at 120 degrees/second. E/I values increased slightly with increasing age (Table 1). There were statistically significant differences between age groups with respect to left $\mathrm{E} / \mathrm{I}(120$ degrees/second) values $(p<0.002)$ and the $p$ value $(p=0.054)$ was close to the significance level with respect to left E/ I (30 degrees/second) values. There were statistically significant differences between the age groups of 20-29 and 60-upper ages $(p<0.004)$, and $30-39$ and $60-$ upper ages $(p<0.02)$ with respect to left $\mathrm{E} / \mathrm{I}$ (120 degrees/second) values in the post hoc analysis. There were no significant differences between male and female subjects with respect to E/ I ratios at 30 and 120 degrees/second $(\mathrm{p}>0.05)$ (Table 2). E/I ratios at 30 and 120 degrees/second were not different between the dominant and nondominant limbs $(\mathrm{p}>0.05)$ (Table 3$)$.

\section{DISCUSSION}

The interesting finding in our study was the slight increase in E/I ratio with increasing age. In the study of Baumhauer et al. ${ }^{5}$ the $\mathrm{E} / \mathrm{I}$ ratio at 30 degrees/second was reported as $89.4 \pm 0.19$ in athletes aged between 18-23 years. Willems et al. ${ }^{7}$ reported the E/I ratios as $1.00 \pm 0.36$ and $1.02 \pm 0.26$ for 30 and 120 degrees/second angular velocities, respectively, in a study population consisting of students aged between 17-26 years. In another study performed in a study population with a mean age of 21.6 years, E/I ratios were between 0.94 and 1.10 at 30 degrees/second and between 0.61 and 0.75 at 120 degrees/second ${ }^{3)}$. Although the ratios reported in these younger population studies were lower than the ratios we observed in the present study, these comparisons further support our conclusion that the E/I ratio slightly increases with increasing age. This phenomenon persisted in both slow (30 degrees/second) and medium high (120 degrees/second) angular velocities. Decreasing knee extensor and flexor peak torque values in older subjects have been reported, but the change in agonist/antagonist ratio was not investigated previously ${ }^{13)}$. Our results suggest that strength decline in agonist and antagonist muscle groups may not be proportionate. This phenomenon may be due to changes in daily activities due to increasing age, decreased mobility or altered biomechanics as a result of musculosceletal abnormalities like osteoarthritis. Future studies which investigate the effect of these possible factors may identify the actual causes.

Another important finding of our study was the similar E/I ratios observed in male and female subjects at both 30 and 120 degrees/second angular velocities. There were no statistically significant differences between male and female subjects. Although higher knee extensor and flexor peak torque values in male subjects than female subjects have been reported previously, the effect of gender on ankle E/I ratio has not been investigated ${ }^{13-15}$. Wong et $\mathrm{al}^{18}$ ). found no significant differences between males and females in inversion and eversion peak torque when normalized for body weight. Similarly, no significant sex difference in inversion or eversion strengths was found when normalized to unit of body size in healthy young adults in the study of Ottaviani et al. ${ }^{19)}$. Although these two studies showed the similarity of evertor and invertor peak torque/body weight ratios in both sexes, our present study is the first to demonstrate the similarity of E/I ratios in male and female subjects.

In our present study, no statistically significant differences between dominant and non- dominant limbs with respect to E/I ratios at both 30 and 120 degrees/second angular velocities were found. This finding is important because higher or lower peak torque values according to the direction of movement in the dominant and non-dominant limbs have been reported previously ${ }^{16)}$. In that study shoulder adduction, extension and internal rotation were greater on the dominant side whereas abduction and external rotation were greater on the non- dominant side. Although we could not find any previous study which had investigated the effect of 
Table 1. Ankle Evertor//Invertor (E/I) maximal torque ratios in different age groups

\begin{tabular}{lcccc}
\hline $\begin{array}{c}\text { Age groups } \\
\text { (years) }\end{array}$ & $\begin{array}{c}\text { Right E/I(30) } \\
\text { (Dominant) }\end{array}$ & $\begin{array}{c}\text { Left E/I (30) } \\
\text { (Non-dominant) }\end{array}$ & $\begin{array}{c}\text { Right E/I(120) } \\
\text { (Dominant) }\end{array}$ & $\begin{array}{c}\text { Left E/I (120) } \\
\text { (Non-dominant) }\end{array}$ \\
\hline $20-29(\mathrm{n}=30)$ & $110.1 \pm 25.4$ & $106.2 \pm 25.1$ & $101.7 \pm 21.4$ & $98.5 \pm 19.1$ \\
$30-39(\mathrm{n}=12)$ & $116.3 \pm 21.2$ & $111.1 \pm 24.2$ & $108.3 \pm 20.1$ & $99.8 \pm 18.5$ \\
$40-49(\mathrm{n}=21)$ & $127.6 \pm 24.8$ & $129.3 \pm 28.1$ & $108.3 \pm 21.7$ & $111.6 \pm 26.2$ \\
$50-59(\mathrm{n}=9)$ & $119.3 \pm 20.4$ & $120.2 \pm 23.2$ & $113.8 \pm 17.8$ & $119.1 \pm 30.5$ \\
60-upper(n=7) & $123.2 \pm 29.6$ & $118.9 \pm 32.2$ & $115.7 \pm 20.8$ & $134.7 \pm 21.2$ \\
p value & 0.175 & 0.054 & 0.382 & 0.002 \\
\hline
\end{tabular}

Table 2. Ankle Evertor//Invertor (E/I) maximal torque ratios in male and female subjects

\begin{tabular}{lcccc}
\hline & $\begin{array}{c}\text { Right E/I(30) } \\
\text { (Dominant) }\end{array}$ & $\begin{array}{c}\text { Left E/I (30) } \\
\text { (Non-dominant) }\end{array}$ & $\begin{array}{c}\text { Right E/I(120) } \\
\text { (Dominant) }\end{array}$ & $\begin{array}{c}\text { Left E/I (120) } \\
\text { (Non-dominant) }\end{array}$ \\
\hline Male $(\mathrm{n}=32)$ & $114.2 \pm 26.7$ & $115.0 \pm 31.3$ & $103.0 \pm 20.8$ & $106.9 \pm 27.6$ \\
Female $(\mathrm{n}=47)$ & $120.2 \pm 23.6$ & $115.9 \pm 24.6$ & $109.9 \pm 20.7$ & $108.3 \pm 23.2$ \\
p value & 0.297 & 0.898 & 0.158 & 0.812 \\
\hline
\end{tabular}

Table 3. Ankle Evertor//Invertor (E/I) maximal torque ratios in dominant and non-dominant limbs

\begin{tabular}{lccc}
\hline & Dominant Ankle & Non-dominant Ankle & p value \\
\hline $\begin{array}{l}\text { Evertor/Invertor peak torque } \\
\text { ratios at angular velocity of }\end{array}$ & $118.0 \pm 25.4$ & $115.7 \pm 27.3$ & 0.528 \\
30 degrees/second & & & \\
\hline $\begin{array}{l}\text { Evertor/Invertor peak torque } \\
\text { ratios at angular velocity of }\end{array}$ & $107.4 \pm 21.2$ & $107.6 \pm 25.0$ & 0.941 \\
120 degrees/second & & & \\
\hline
\end{tabular}

limb dominance on ankle E/I ratio, Bernier et $\mathrm{al}^{8}$. found no significant difference between the dominant and non-dominant eccentric strengths of ankle invertors and evertors using a Kin Com dynamometer at a velocity of 90 degrees/second. We consider that our study is important because it is the first study to reveal the similarity of concentric ankle $\mathrm{E} / \mathrm{I}$ ratios on the dominant and non-dominant sides. A point to mention here is that the dominance of the limb was determined by asking which hand was used for writing and eating in our study. As the dominant cerebral hemisphere determines the dominance of the limbs we believe that inaccordance with upper and lower limb dominance is rare. However, it would have been better to have determined the dominance of the lower limb specifically. This point is a limitation of our study.

In conclusion, according to our results, ankle evertor/invertor peak torque ratios are affected by age, but not by the dominance of the limb and the patient's gender. The ratios observed in different age groups in our study could be used as reference values in clinical evaluations and rehabilitation programs without taking into account the dominance of the limb and the patient's gender. Future studies with larger sample sizes may further demonstrate the relationship between age and the ankle evertor/invertor peak torque ratios.

\section{REFERENCES}

1) Hartsell HD, Spaulding SJ: Eccentric/concentric ratios at selected velocities for the invertor and evertor muscles of the chronically unstable ankle. Br J Sports Med, 1999, 33(4): 255-258.

2) Kaminski TW, Perrin DH, Gansneder BM: Eversion strength analysis of uninjured and functionally unstable ankles. J Athl Train, 1999, 34(3): 239-245.

3) Kaminski TW, Buckley BD, Powers ME, et al.: Effect of strength and proprioception training on eversion to inversion strength ratios in subjects with unilateral functional ankle instability. Br J Sports Med, 2003, 37(5): 410-415. 
4) Fox J, Docherty CL, Schrader J, et al.: Eccentric plantar-flexor torque deficits in participants with functional ankle instability. J Athl Train, 2008, 43(1): 51-54.

5) Baumhauer JF, Alosa DM, Renstrom AF, et al.: A prospective study of ankle injury risk factors. Am J Sports Med, 1995, 23(5): 564-570.

6) Baumhauer JF, Alosa DM, Renström AF, et al.: Testretest reliability of ankle injury risk factors. Am J Sports Med, 1995, 23(5): 571-574.

7) Willems T, Witvrouw E, Verstuyft J: Proprioception and muscle strength in subjects with a history of ankle sprains and chronic instability. J Athl Train, 2002, 37(4): 487-493.

8) Bernier JN, Perrin DH, Rijke A: Effect of unilateral functional instability of the ankle on postural sway and inversion and eversion strength. J Athl Train, 1997, 32(3): 226-232.

9) Konradsen L, Magnusson P: Increased inversion angle replication error in functional ankle instability. Knee Surg Sports Traumatol Arthrosc, 2000, 8(4): 246-251.

10) Lentell G, Baas B, Lopez D: The contributions of proprioceptive deficits, muscle function, and anatomic laxity to functional instability of the ankle. J Orthop Sports Phys Ther, 1995, 21(4): 206-215.

11) Draganich LF, Jaeger RJ, Kralj AR: Coactivation of the hamstrings and quadriceps during extension of the knee. J Bone Joint Surg Am, 1989, 71(7): 1075-1081.

12) Wilkerson GB, Pinerola JJ, Caturano RW: Invertor vs. evertor peak torque and power deficiencies associated with lateral ankle ligament injury. J Orthop Sports Phys Ther, 1997, 26(2): 78-86.

13) Ostchega Y, Dillon CF, Lindle R, et al.: Isokinetic leg muscle strength in older Americans and its relationship to a standardized walk test: data from the national health and nutrition examination survey 1999-2000. J Am Geriatr Soc, 2004, 52(6): 977-982.

14) Katsiaras A, Newman AB, Kriska A, et al.: Skeletal muscle fatigue, strength, and quality in the elderly: the Health ABC Study. J Appl Physiol, 2005, 99(1): 210226 (Epub 2005, Feb. 17).

15) Pincivero DM, Gandaio CM, Ito Y: Gender-specific knee extensor torque, flexor torque, and muscle fatigue responses during maximal effort contractions. Eur J Appl Physiol, 2003, 89(2): 134-141.

16) Lertwanich $P$, Lamsam $C$, Kulthanan $T$ : Difference in isokinetic strength of the muscles around dominant and nondominant shoulders. J Med Assoc Thai, 2006, 89(7): 948-952.

17) Donatelli R: The biomechanics of the foot and ankle. 2nd edition. Philadelphia: FA Davis Co, 1996.

18) Wong DL, Glasheen-Way M, Andrews LF: Isokinetic evaluation of the ankle invertors and evertors. J Orthop Sports Phys Ther, 1984, 5(5): 246-252.

19) Ottaviani RA, Ashton-Miller JA, Wojtys EM: Inversion and eversion strengths in the weightbearing ankle of young women. Effects of plantar flexion and basketball shoe height. Am J Sports Med, 2001, 29(2): 219-225. 